\title{
AÇÕES DE DIVULGAÇÃO DE QUÍMICA NA CASA DA DESCOBERTA - CENTRO DE DIVULGAÇÃo DE CIÊNCIA DA UNIVERSIDADE FEDERAL FLUMINENSE
}

\author{
Márcia N. Borges*, Carlos Magno R. Ribeiro, Denise R. Araripe, Eluzir P. Chacon e Lucidéa G. R. Coutinho \\ Instituto de Química, Universidade Federal Fluminense, Campus do Valonguinho, 24020-141 Niterói - RJ / Casa da Descoberta, \\ Instituto de Física, Campus da Praia Vermelha, Av. Litorânea, s/n, Niterói - RJ, Brasil \\ Daisy M. Luz \\ Instituto de Física, Universidade Federal Fluminense, Campus da Praia Vermelha, Av. Litorânea, s/n, Niterói - RJ / Casa da \\ Descoberta, Instituto de Física, Campus da Praia Vermelha, Av. Litorânea, s/n, Niterói - RJ, Brasil \\ Recebido em 11/12/10; aceito em 8/6/11; publicado na web em 22/7/11
}

\begin{abstract}
ACTIONS REGARDING THE DISSEMINATION OF CHEMISTRY AT CASA DA DESCOBERTA - A SCIENTIFIC DISSEMINATION CENTER OF THE FLUMINENSE FEDERAL UNIVERSITY. This paper describes the main activities regarding scientific dissemination in the field of Chemistry at Casa da Descoberta (CD) - a Scientific Dissemination Center of the Fluminense Federal University. It presents a brief history of CD and discusses the difficulties concerning the dissemination of Chemistry at Scientific Dissemination Centers. This work also approaches some activities developed throughout the years: experiments performed in relation to the visitors' daily life, training of monitors to act as mediators in the non-formal teaching of Chemistry, production of dissemination materials, elaboration of books, as well as activities that relate formal to non-formal education.
\end{abstract}

Keywords: scientific dissemination; Chemistry; education.

\section{INTRODUÇÃO}

Desde o início do movimento construtivista no Brasil, professores e pesquisadores do Ensino de Ciências vêm empregando metodologias de ensino que motivam os estudantes do Ensino Fundamental e Médio a construir conceitos e generalizações aparentemente abstratos e de difícil entendimento. ${ }^{1,2}$ Essas metodologias englobam variadas técnicas de experimentação e debates motivadores em salas de aula.

A estruturação de um ambiente propício à realização de atividades práticas e instrumentais permite o processo de interação entre o aprendiz e o objeto de estudo, somado à cooperação social. Tais critérios são importantes no desenvolvimento das funções psicológicas superiores e, portanto, da aprendizagem. ${ }^{3,4}$ No entanto, a aprendizagem em si é um fenômeno cultural, onde são essenciais tanto os mediadores instrumentais - conteúdos, ferramentas e tecnologias - quanto os mediadores sociais - os interagentes que participam do processo de ensino-aprendizagem, sejam professores, pais, colegas, meio ambiente, etc. Consequentemente, a ênfase nos aspectos sociais do Ensino de Química tem sido a principal metodologia para conectar o que se ensina nas escolas com o dia-a-dia dos alunos. ${ }^{5,6} \mathrm{~A}$ maneira pela qual o cientista pode se aproximar do cidadão comum e conquistar mais adeptos que se interessem em vencer os desafios que a Ciência nos impõe é socializar o conhecimento. ${ }^{7}$ Dentro deste contexto, a divulgação científica assume um papel fundamental, pois significa expandir a Ciência para além dos muros acadêmicos, o que requer a criação de uma forma de comunicação da Ciência acessível a não especialistas.

Uma maneira abrangente de divulgação científica tem sido o uso da internet, na qual é possível encontrar vídeos, jogos, simulações de experimentos, dentre outras. Apesar da importância dessa ferramenta de divulgação, ela ainda não é acessível à maioria da população e não

\footnotetext{
*e-mail: gqomarcia@vm.uff.br
}

favorece as trocas entre o educador e o educando, fator importante no desenvolvimento do processo educacional. Além disso, existe o risco de incorrer em equívocos científicos, caso as informações não sejam adequadamente discutidas e corroboradas por avaliadores competentes. Técnicas tradicionais de divulgação da Química geralmente utilizadas incluem shows de química, demonstração de experimentos, jogos, gincanas e peças teatrais. ${ }^{8,9}$ A divulgação científica pode ser ampliada se for associada a um trabalho contínuo e sistemático, possível nos Centros e Museus de Ciências, além de outros espaços de divulgação científica, principalmente no que se refere à sua abrangência e ao número de pessoas atingidas, uma vez que as atividades podem ser feitas também de forma itinerante. ${ }^{10-12}$

\section{CENTROS E MUSEUS DE CIÊNCIAS}

A utilização de Museus de Ciências como oficinas do saber tem aumentado, nas últimas décadas, a importância destes espaços sócio-pedagógicos como disseminadores do conhecimento científico. Pode-se definir, de maneira simplificada, que Centros e Museus de Ciências são espaços públicos ou privados que têm como principal objetivo mediar a relação entre as pessoas e a Ciência, através da exposição de objetos de interesse científico e educacional, usando uma linguagem simples e concisa. São também chamados de espaços de educação não formal, uma vez que a proposta educativa não está vinculada a um sistema estruturado de hierarquização de saberes que dão origem a uma titulação, como ocorre, por exemplo, nas escolas. ${ }^{13}$

A construção de experimentos interativos, divertidos, com conceitos análogos à tecnologia moderna tem sido fundamentada no paradigma da simulação e construção de modelos científicos. ${ }^{14,15} \mathrm{~A}$ transformação dos conceitos se faz de forma dinâmica entre o modelo já visto e o que se pretende re-estruturar no universo cognitivo. ${ }^{16} \mathrm{Neste}$ escopo a interatividade entre o observador e o objeto/fenômeno em estudo se dá pela modelagem inicial de fenômenos antes considerados 
abstratos, através da percepção de imagens concretas, seus atributos e correlações com imagens difusas do pré-conhecimento. No contexto da interatividade são exploradas as analogias e o espaço da conceituação, tornando a modelagem mais abrangente. A natureza da interação e as possibilidades de aprendizagem podem vir a ser determinadas, portanto, pelos ambientes e propostas que envolvem o público antes, durante e após a visita a um museu interativo de Ciências.

Desde que o Departamento de Popularização e Difusão da Ciência e Tecnologia do Ministério de Ciência e Tecnologia (MCT) promoveu a primeira Semana Nacional de Ciência e Tecnologia (SNCT) em 2004, o número de ações de divulgação de Ciências em espaços formais e não formais de educação no Brasil aumentou significativamente. ${ }^{17} \mathrm{~A}$ adesão cada vez maior de instituições públicas e privadas ao evento (Figura 1) e o aumento de fomento de projetos na área de divulgação científica são parâmetros que evidenciam que a educação científica não pode ficar restrita somente à educação formal. ${ }^{18}$

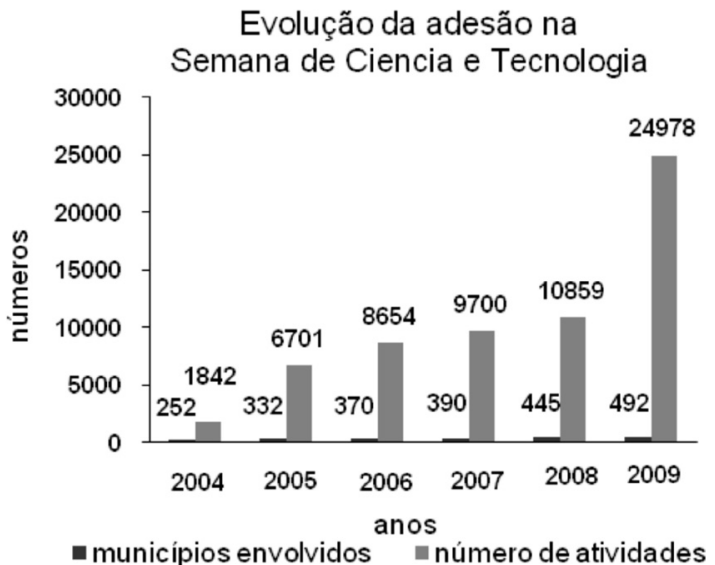

Figura 1. Evolução da participação de municípios e número de atividades realizadas na SNCT de 2004 a 2009

Em seu último catálogo, a Associação Brasileira de Centros e Museus de Ciências (ABCMC) relacionou quase duas centenas de Museus e Centros de Ciências espalhados por todo o Brasil, dentre os quais está a Casa da Descoberta (CD), que é um espaço museal pertencente à Universidade Federal Fluminense - UFF, que expõe mais de 50 experimentos interativos nas áreas de Física, Química, Matemática e Biologia. ${ }^{12}$

\section{A Química nos Centros e Museus de Ciências}

Apesar do grande número de Museus de Ciências no Brasil e no exterior, nota-se que há uma dificuldade de se encontrar experimentos interativos que divulguem a Química com a mesma intensidade com que se verifica a existência de aparatos relacionados a outros ramos das ciências exatas, como a Física e a Matemática. ${ }^{19-21}$ Identificam-se aqui três fatores que acreditamos que possam influenciar na baixa divulgação da Química em Centros e Museus de Ciências:

1) O formato da maioria dos Centros e Museus de Ciências brasileiros é inspirado no Exploratorium, criado nos Estados Unidos na década de 1960, com um acervo expositivo baseado no construtivismo, incentivando a interatividade física com os objetos da exposição como forma de atingir a aprendizagem significativa. ${ }^{13}$ Essa nova perspectiva de museu fez um grande sucesso e tornou-se um modelo, incluindo a comercialização dos seus equipamentos que foram exportados para vários locais do mundo. Os equipamentos construídos atendem bem a explicação de diversos fenômenos nas áreas da Física e da Matemática, e podem ser manuseados pelo visitante leigo com segurança, mas o mesmo não acontece com os experimentos de Química, que exigem pessoal treinado para manusear os reagentes.

2) O segundo obstáculo é econômico, pois para demonstrar reações de maneira contínua a experiência torna-se cara, já que exige a manutenção de equipamentos, reposição de reagentes, obras de infraestrutura com relação a sistemas de exaustão e segurança, além de descarte do rejeito.

3) Por fim, há a dificuldade na preparação do mediador, pois, caso se opte pela realização de experimentos, será necessário investir na formação de Químicos, profissionais ou estudantes, que nem sempre são estimulados a reconhecer Centros e Museus de Ciências como mais uma área de atuação profissional.

Observa-se que, de modo geral, os Museus e Centros de Ciências procuram resolver a ausência da Química no espaço museal, disponibilizando kits de experimentos de Química para que os professores realizem os ensaios em suas salas de aula. ${ }^{22,23}$ Sem dúvida, essa prática contribui para a melhoria da aprendizagem em muitas escolas, mas, para os estudantes que visitam e se divertem aprendendo nos Museus de Ciências, fica a sensação de que a Química está excluída desses ambientes.

Desde que a Casa da Descoberta foi implementada de forma definitiva na UFF, em 2000, o Núcleo de Pesquisa em Ensino de Química (NUPEQUI-UFF) associou-se a ela a fim de divulgar a Química usando uma abordagem lúdica e interdisciplinar. Para isso, usou-se como principal metodologia a demonstração de experimentos interativos para o público visitante.

Uma vez que em 2011 é celebrado o Ano Internacional da Química, promovido pela UNESCO e IUPAC,,${ }^{24}$ consideramos importante difundir as ações de divulgação da Química que vêm ocorrendo há 10 anos na Casa da Descoberta, assim como inspirar pesquisadores, professores e estudantes a utilizar os Centros e Museus de Ciências como um ambiente com grande potencial de articulação de ensino, pesquisa e extensão.

\section{DIVULGAÇÃO DA QUÍMICA NA CASA DA DESCOBERTA}

A divulgação da Química na CD ocorre inicialmente com a utilização de aparatos e experimentos em seu espaço físico, escolhidos e desenvolvidos pelos participantes da CD: professores e monitores. O projeto "Reações Divertidas" funciona com diversos kits de experimentos em uma bancada de química que atua de forma contínua e sistemática junto ao público estudantil e visitante em geral com alcance relevante na região fluminense, uma vez que a CD recebe milhares de visitantes anualmente (Figura 2). O trabalho desenvolvido se caracteriza não só pela divulgação da Química como na formação de químicos ampliando horizontes de atuação, uma vez que ainda há uma grande carência desses profissionais presentes em Centros de divulgação de Ciências.

A Figura 3 apresenta a origem dos visitantes da CD em 2009. Podemos perceber que a maioria vem do município de Niterói e adjacências.

Uma atuação bem estabelecida pela CD para a divulgação científica é a atividade de itinerância, na qual os aparatos e experimentos são deslocados para escolas, praças e eventos como congressos e reuniões científicas, SNCT. Iniciada em 2003, a itinerância é realizada em praças e espaços públicos de Niterói, e também em outros municípios do Estado do Rio de Janeiro. Foram visitados os municípios de Rio de Janeiro, Duque de Caxias, Mangaratiba e Rio das Ostras, os quais distam de Niterói 13,39, 118 e 153 km, respectivamente. ${ }^{25}$ O público que vem sendo alcançado nessas atividades é incontável, sobretudo quando em praça pública, momento no qual se tem observado a 


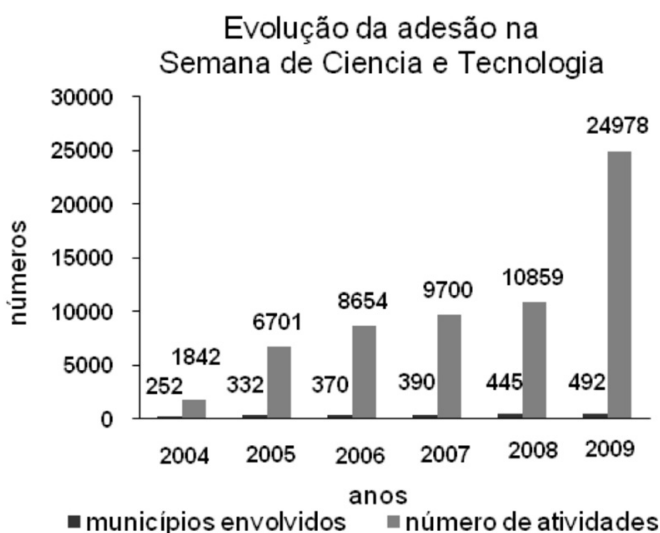

Figura 2. Número de visitantes na $C D$

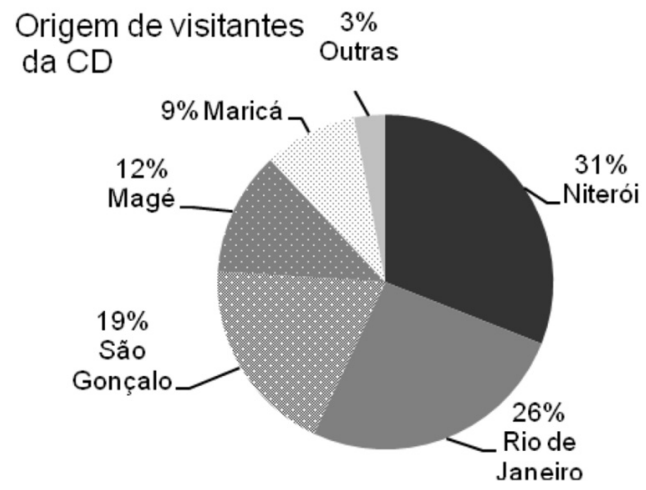

Figura 3. Distribuição de visitantes da CD por localidade de origem

empolgação demonstrada por uma gama enorme de indivíduos de diversas características socioeconômicas e culturais.

\section{Escolha dos experimentos de Química para a CD}

A escolha dos experimentos de Química a serem apresentados na Casa da Descoberta passa por um processo de seleção que começa com a pesquisa na literatura. Em seguida, são escolhidos experimentos que sejam adequados ao nosso espaço museal. Logo após, tais experimentos são reproduzidos e/ou adaptados no laboratório de pesquisa em Ensino de Química. Depois de aprovado, o experimento é levado para a Casa da Descoberta, para verificar a resposta do público visitante. De acordo com a reação do público e a funcionalidade real do experimento, ele passa a fazer parte do acervo permanente ou não. Por exemplo, experimentos que usam alimentos perecíveis não são práticos para as condições de manutenção diária. Assim, a CD apresenta-os eventualmente em atividades de itinerância ou de acordo com o perfil dos visitantes.

De fato, escolher experimentos de Química que possam ser realizados dentro de Museus para todo o tipo de público é uma tarefa bastante complicada. Os cuidados a serem tomados em relação aos materiais e reagentes empregados e o descarte dos resíduos gerados são fatores que dificultam a presença da Química nos Centros e Museus de Ciência. Mesmo diante dessas dificuldades, em 2000 a Casa da Descoberta investiu na montagem de uma bancada para a realização de experimentos simples e divertidos de Química para despertar o interesse do visitante de um modo geral, principalmente estudantes do ensino fundamental e médio. Desta maneira foi desenvolvido o projeto "Reações Divertidas", cujas práticas selecionadas, resumidas na Tabela 1, enfocam como principais características: segurança; uso mínimo de reagentes; ênfase no uso de materiais alternativos; reações com produção de um ou mais efeitos de apelo sensorial como, por exemplo, cor, chama, barulho, cheiro; máximo de interatividade; rapidez de execução; relação dos temas tratados com as questões do cotidiano. Os critérios usados vêm sendo empregados em outras iniciativas que têm por objetivo demonstrar experimentos de Química para um público leigo ou escolar fora do ambiente mais adequado, que seria um laboratório. ${ }^{19-20,26} \mathrm{Na} \mathrm{CD}$, necessariamente não há uma ordem de prioridade com relação a esses critérios para a seleção dos experimentos que fazem parte do acervo na bancada de Química. Do ponto de vista educativo/institucional, prima-se pela segurança e potencialidade de aprendizagem. No entanto, o impacto do experimento tem sido muito importante para o público, pelo menos no primeiro momento. Uma vez que a maioria das visitas são previamente agendadas, o perfil do visitante acaba sendo determinante na seleção final do que será apresentado a cada tipo de público, o que requer treinamento e bom senso da equipe.

\section{Temas abordados nos experimentos de Química da CD}

A popularização da Ciência é uma necessidade para o pleno exercício da cidadania. Temas que envolvem tomadas de decisão relacionadas a consumo, combustíveis, meio ambiente, por exemplo, quase sempre despertam uma curiosidade que muitas vezes leva a uma discussão crítica, ainda que inicialmente o visitante não tenha um embasamento científico sobre o assunto. Se o visitante é um estudante ou professor, o monitor estimula que os temas sejam explorados mais detalhadamente na sala de aula.

Assim, os experimentos selecionados para serem realizados na Casa da Descoberta, além de passarem pelo processo de seleção baseado nos critérios descritos anteriormente, são também escolhidos pela facilidade de serem associados com curiosidades do dia-a-dia.

A Tabela 1 apresenta alguns dos experimentos realizados na $\mathrm{CD}$, os temas sociais e ambientais correlacionados com a Química.

A seguir são apresentados os resumos dos experimentos para um melhor entendimento de sua execução e proposta.

1- Gotas Flutuantes - A uma mistura de água e álcool é adicionada uma gota de óleo. Observa-se a esfera de óleo flutuando no interior da mistura. O efeito é causado pela diferença de densidade e solubilidade dos componentes da mistura.

2- Destilação do Café/da Água do Mar - Uma mistura de café é colocada em um sistema de destilação clássico. A mistura é destilada, sobrando a borra de café no balão de destilação. Colhe-se a água ao final do condensador. Também variamos o experimento usando água do mar.

3- Purpurina de Iodo - Neste experimento observa-se iodo sublimando. As pequenas partículas de cor lilás flutuam no ar como se fosse uma chuva de purpurina.

4- Submarino na Garrafa PET- Em uma garrafa PET vedada, cheia de água, uma caneta do tipo esferográfica sem carga é equilibrada com o auxílio de clips na posição vertical. A caneta sobe e desce à medida que se exerce com as mãos maior ou menor pressão sobre a garrafa.

5- Lança-chamas - Uma chama é produzida quando um tubo de ensaio contendo parafina em ebulição é colocado em um recipiente contendo água fria. As propriedades dos hidrocarbonetos são discutidas neste experimento.

6- Chamas Coloridas - A queima dos sais de alguns metais produz chamas coloridas. Esta propriedade é usada desde a antiguidade na confecção de fogos de artifício coloridos.

7- Estrela Colorida - Um desenho de uma estrela de 6 pontas é usado para explicar conceitos de cores primárias e secundárias de pigmentos. Cada vértice alternado da estrela representa uma cor 
Tabela 1. Principais experimentos de Química abordados na CD

\begin{tabular}{lll}
\hline Experimentos & Tópicos de Química & Temas articulados \\
\hline 1- Gotas Flutuantes & Propriedades da matéria: densidade e solubilidade & Poluição da água e combustíveis \\
2- Destilação da Água do Mar/do Café & Propriedades físicas e separação de misturas & Água e purificação de substâncias \\
3- Purpurinas de Iodo & Propriedades da matéria: mudança de estado físico & Mudanças de estado físico no meio ambiente \\
4- Submarino na Garrafa PET & Propriedades físicas da matéria: propriedade de gases e líquidos & Reciclagem e submarino \\
5- Lança-chamas & Propriedades físicas da matéria e mudanças de estado físico e & Combustíveis \\
& reações de combustão & Fogos de artifício e segurança no uso e radiação \\
6- Chamas Coloridas & Espectro eletromagnético e modelo atômico de Bohr & Pigmentos, intoxicação e radiação \\
7- Estrela Colorida & Misturas e espectro eletromagnético & Materiais isolantes, condutores e solubilidade \\
8- Acende ou Não Acende? & Condutividade elétrica em substâncias e soluções, ligações químicas & Combustíveis alternativos \\
9- Foguete Químico & Transformação química e obtenção de energia reações de combustão & Combustão e meio ambiente \\
10- Fogo Mágico & Termoquímica, oxidação e redução & Material térmico e sensação térmica \\
11- “Tá quente ou tá frio?” & Termoquímica & Equilíbrio ácido-base no corpo humano \\
12- Canhão Químico & Comportamento de gases e equilíbrio ácido/base & Remoção de manchas e ácidos e bases utilizados \\
13- Sangue do Diabo & Equilíbrio químico, acidez e basicidade & na saúde \\
14- Agulhas de Prata & Corrosão de metais & Galvanoplastia e corrosão \\
15- Papel à Prova de Fogo & Termoquímica e capacidade calorífica da água & Papel; propriedades da água e reciclagem \\
16- Bafão & Reação ácido-base e equilíbrio químico & Bafômetro e equilíbrio ambiental
\end{tabular}

primária e uma secundária, sendo que a secundária sempre se situa entre as cores primárias de origem. Esse experimento também é associado à Matemática. ${ }^{27}$

8- Acende ou Não Acende? - Neste experimento diversos materiais são conectados a dois fios de cobre ligados a um circuito elétrico e a uma lâmpada. Se o material for bom condutor de corrente elétrica, a lâmpada acenderá; se não, ela permanecerá apagada. A natureza química dos materiais determinará o resultado.

9- Foguete Químico - Uma garrafa PET borrifada com álcool é suspensa paralela a um fio de arame unido a duas hastes em posição ascendente, de maneira que a garrafa possa deslizar sobre o fio. A garrafa movimenta-se como um foguete quando o álcool entra em combustão devido à aproximação da chama de uma vela à tampa da garrafa convenientemente furada

10- Fogo Mágico - Substâncias que reagem rapidamente entre si e liberam grande quantidade de calor provocam a queima de material combustível na presença de oxigênio.

11- Tá quente ou tá frio? - A dissolução de sais em água com a liberação ou a absorção de calor ocorre simultaneamente em dois tubos de ensaio. Quando a pessoa segura um tubo em cada mão e depois troca os tubos de mãos, experimenta a troca de sensação térmica.

12- Canhão Químico - Vinagre e bicarbonato de sódio são misturados em um tubo de ensaio fechado por uma rolha. A reação imediata libera gás carbônico que atira a rolha a uma longa distância.

13- Sangue do Diabo - Uma mistura vermelha torna-se incolor em poucos minutos ao entrar em contato com um tecido branco. A volatilidade e a basicidade dos componentes da mistura provocam o efeito.

14- Agulhas de Prata-Agulhas são formadas em um fio de cobre ao ser submerso em uma solução de nitrato de prata. Este processo ocorre devido à oxidação e à redução dos metais presentes.

15- Papel à Prova de Fogo - Coloca-se um pouco de água em um uma panela feita de papel. Ao aquecer este papel suavemente é possível observar que a água no interior do papel ferve sem o papel pegar fogo. $\mathrm{O}$ que acontece com a energia térmica liberada pela chama explica o fenômeno.

16- Bafão - Uma solução azul de base, diluída com indicador azul de bromotimol, é colocada em um frasco tipo erlenmeyer. Os visitantes são desafiados pelo monitor a soprar a solução com o auxílio de um canudo, para testar se estão mantendo o hálito saudável. Após alguns sopros a solução muda de cor por conta da presença do gás carbônico em solução. Ao final, o monitor explica os fenômenos envolvidos.

$\mathrm{O}$ uso de experimentos é uma metodologia que tem sido complementada pelo desenvolvimento de outras estratégias de ensino como, por exemplo, o uso do lúdico em jogos como o Quiz da Casa da Descoberta, Bingo de Ciências, e brincadeiras de mágica. Embora ações de divulgação de Química e Museus de Ciência já existam há muitos anos, a Química na CD tem sido um diferencial dos Centros de Divulgação de Ciências no Estado do Rio de Janeiro, uma vez que está presente permanentemente no espaço museal, articulando o ensino formal e não formal de maneira transdisciplinar.

\section{Atuação dos monitores na CD}

Uma das principais características da CD é a presença de monitores que atuam como mediadores, aumentando a interatividade visitante-experimento e relacionando os conceitos científicos presentes em cada experimento com fatos do dia-a-dia, sem a utilização de jargões científicos. Esses monitores são em sua maioria, alunos dos cursos de graduação em Física, Química, Engenharia e Matemática, matriculados nos mais diversos períodos. Todos passam por um curso de formação anual que dura em torno de 3 semanas e recebem, de maneira contínua, orientação com relação à sua atuação junto ao público.

Os monitores que atuam na bancada de Química, são principalmente alunos dos cursos de Química da UFF (bacharelado, licenciatura e industrial) que também participam dos processos de elaboração e seleção dos experimentos. A maioria dos monitores de Química é atraída pela possibilidade de fazer um estágio num ambiente informal, com bolsa e sem pré-requisito curricular. Outro atrativo é a possibilidade de vincular suas atividades às disciplinas de Iniciação à Docência, à Extensão e à Pesquisa. Os monitores permanecem em média 2 anos e saem porque concluem o curso ou porque buscam outras experiências profissionais.

Em estudos preliminares, ${ }^{28,29}$ todos os ex-monitores questionados avaliaram de forma positiva a experiência adquirida na CD. Declara- 
ram que aprender a trabalhar em equipe num contexto multidisciplinar e lidar com todo o tipo de público foram os aspectos de aprendizagem mais marcantes da monitoria. De fato, para os estudantes de Licenciatura, exercitar o ensino num ambiente de educação não formal, onde a velocidade de troca de informações científicas é bastante alta, torna-se uma excelente incursão epistemológica na formação de um professor moderno. Para os futuros bacharéis e químicos industriais, o estágio contribui na formação de recursos humanos estimulados a pesquisar e desenvolver novas tecnologias que coloquem a Química e os químicos de maneira mais significativa dentro dos Centros e Museus de Ciências.

O gráfico da Figura 4 apresenta o número total de monitores entre voluntários e bolsistas que vêm atuando na $\mathrm{CD}$ desde sua implementação, sendo que o número de estudantes de Química por ano é de aproximadamente 4 alunos. Outros monitores, oriundos de cursos como Física e Engenharia, são incentivados a realizarem a apresentação dos experimentos citados anteriormente, o que certamente contribui para maior integração entre os alunos e maior aprendizagem de conceitos da Química. O mesmo acontece com os alunos de Química em relação aos experimentos de Física, Matemática e Biologia. Ressalta-se que o número de bolsas recebidas pelos projetos para os monitores aumentou significativamente e vem se mantendo num número razoavelmente constante, o que indica a valorização das ações realizadas na $\mathrm{CD}$.

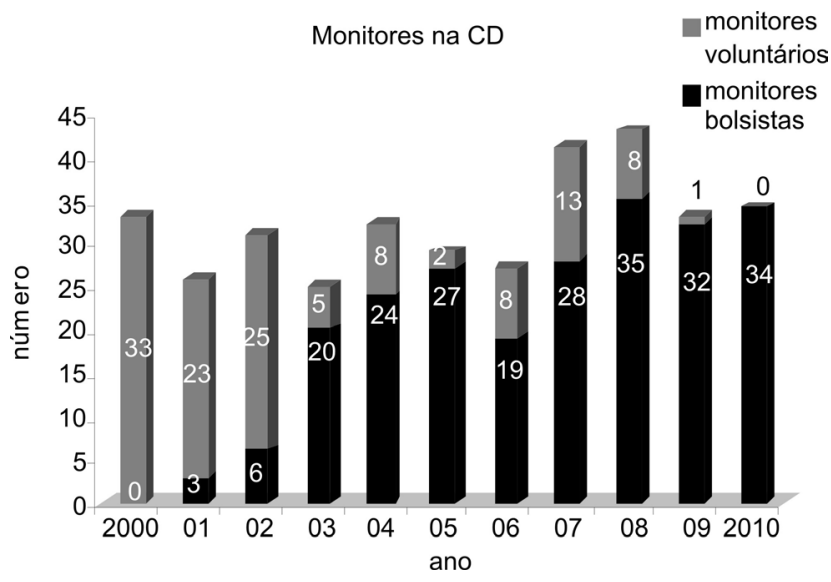

Figura 4. Monitores da CD ao longo dos anos

\section{Outras considerações}

A Química está sendo divulgada na CD há pouco mais de 10 anos e, no entanto, ainda apresenta três dificuldades principais. A primeira é a constante busca por novos experimentos que atendam as condições já citadas anteriormente para renovação do acervo da bancada de Química. Outra dificuldade está relacionada à infraestrutura, como a falta de um espaço específico de Química e almoxarifado, na própria $\mathrm{CD}$, os quais acreditamos que venham a ser reduzidos com a construção da nova sede..$^{30} \mathrm{~A}$ terceira dificuldade vem sendo a de difundir entre os pares a ideia de que a popularização científica deve ser abraçada também pelos Químicos, se constituindo numa área de atuação necessária, entre outros motivos, para despertar interesses e novas vocações na área científica.

A permanência da Casa da Descoberta após 10 anos de existência deve-se a três fatores: a importância que a equipe de docentes e alunos dão a esta atividade, o apoio oferecido pela Universidade em suas diferentes instâncias e, a verba obtida através de projetos submetidos a diferentes órgãos de fomento.

A equipe de professores da CD é formada por docentes dos Institutos de Física, Química, Arte e Comunicação Social e Escola de Arquitetura. A diversidade de formação deste grupo favorece a formulação de atividades e construção de experimentos conceitualmente interdisciplinares. Os alunos, que compõem o grupo de mediadores, participam da avaliação das atividades realizadas e os mais antigos acompanham o estágio dos estreantes. A equipe de mediadores é renovada em pelo menos metade de seus membros a cada ano. Já a Universidade apoia as atividades da CD através da cessão de funcionários e bolsas para os monitores, geralmente oriundas da Pró-Reitoria de Extensão (PROEX). Vale destacar o incentivo que os órgãos de fomento têm destinado aos Centros e Museus de Ciência com editais específicos para a área de Divulgação Científica. Tais editais contemplam a construção de novos experimentos, formação continuada da equipe nesta área específica e participação em Simpósios e Congressos. Desde 2000, ano de criação da CD, já recebemos quase $\mathrm{R} \$ 800.000,00$ (oitocentos mil reais), através de projetos aprovados na FAPERJ (6), CNPq (3), Fundação Vitae (2) e FINEP (1). Firmamos também um convênio com a Eletrobras cujo valor não está incluído no montante acima. Este convênio e a verba recebida pela FINEP estão voltados para a construção da nova sede da Casa da Descoberta, fora do prédio do Instituto de Física e em local que certamente contribuirá para maior visibilidade de nosso projeto.

A importância das atividades realizadas na CD tem sido observada utilizando os seguintes indicadores de impacto junto ao público: interesse demonstrado durante a execução dos experimentos que se expressa de várias maneiras, retorno da visita de professores com novas turmas, retorno de estudantes com familiares e a percepção de um aumento na participação do público nas atividades de itinerância. Assim, pode-se dizer que a CD tem ajudado na disseminação da educação científica formal e não formal, o que tem refletido na geração de produtos bibliográficos, ${ }^{31}$ entrevistas de divulgação científica e inserções na mídia. ${ }^{32}$

\section{CONCLUSÃO}

A avaliação positiva dos visitantes demonstra que a $\mathrm{CD}$ vem cumprindo seus objetivos ao longo dessa década, que são contribuir para aproximar, difundir e divulgar a Ciência para o cidadão comum, principalmente em Niterói e na Região Fluminense. Ao mesmo tempo, tem ajudado a romper estigmas sobre a Química, mostrando a beleza e a relevância desta Ciência.

\section{AGRADECIMENTOS}

A todos os professores, alunos e funcionários que vêm contribuindo direta ou indiretamente nas ações desenvolvidas na $\mathrm{CD}$, em especial aos Profs. L. R. Costa e N. A. de Souza. À Universidade Federal Fluminense. Às agências de fomento CNPq/FINEP, FAPERJ, MEC/PROEXT, Fundação Vitae e Eletrobras.

\section{REFERÊNCIAS}

1. Mortimer, E. F.; Investigações em Ensino de Ciências 1996, 1, 20.

2. Zanon, L. B.; Maldaner, O. A., orgs.; Fundamentos e Propostas de Ensino de Química para a Educação Básica no Brasil, Ed. Unijuí: Ijuí, 2007.

3. Gonçalves, F. P.; Marques, C. A.; Investigação em Ensino de Ciências 2006, 11, 219.

4. Vygotsky, L. S.; Psicologia Pedagógica, Artmed: Porto Alegre, 2003.

5. Santos, W. L. P.; Mortimer, E. F.; Ciência \& Educação 2001, 7, 95.

6. Chassot, A. I.; Rev. Bras. Edu. 2003, 26, 89.

7. Santos, W. L. P.; Schnetzler, R. P.; Educação em Química: Compromisso com a Cidadania, Ed. Unijuí: Ijuí, 1997.

8. Arroio, A.; Honorio, K. M.; Weber, K. C.; Quim. Nova 2006, 29, 173. 
9. http://www.searadaciencia.ufc.br/arte/teatro/teatro.htm, acessada em Julho 2011.

10. http://gepeq.iq.usp.br/, acessada em Julho 2011.

11. Marandino, M.; Rev. Bras. Edu. 2004, 26, 95.

12. Associação Brasileira de Centros e Museus de Ciência; Centros e Museus de Ciências do Brasil, UFRJ/FCC/Casa da Ciência: Fiocruz/ Museu da Vida: Rio de Janeiro, 2009.

13. Marandino, M., org.; Educação em Museus: a Mediação em Foco, Geenf/FEUSP: São Paulo, 2008.

14. Greca, I. M.; Moreira, M. A.; Investigações em Ensino de Ciências 2002, 7,31 .

15. Moreira, M. A.; Lagreca, M. C. B.; Investigações em Ensino de Ciências 1998, 3,83 .

16. Moreira, M. A.; Masini, E. F. S.; Aprendizagem Significativa: a Teoria de David Ausubel, 2a ed., Centauro: São Paulo, 2006.

17. MCT, Semana Nacional de Ciência e Tecnologia, 2004-2010, encarte de divulgação, 2010.

18. Massarani, L.; Moreira, I.; Brito, F.; Ciência e Público: Caminhos da Divulgação Científica no Brasil, Casa da Ciência; Centro Cultural de Ciência e Tecnologia da UFRJ: Rio de Janeiro, 2002.

19. Silberman, R. G.; Trautmann, C.; Merkel, S. M.; J. Chem. Educ. 2004, $81,51$.

20. Bonatto, M. P. O.; Bevilaqua, D. V.; Silva A. C.; Freitas, C. S.; Macedo, A.; Galvão, F. W.; Nogueira, V. S.; Iniciação à Química no Museu da Vida, FIOCRUZ: Avaliando Atividades Experimentais Interativas da Bancada de Pasteur, VII Enpec, 2009, http://www.fae.ufmg.br/abrapec/ viempec/7enpec/pdfs/1606.pdf, acessada em Agosto 2010.

21. Pinto, V. M. M.; Tese de Mestrado, Universidade do Porto, Portugal, 2003.
22. http://www.eciencia.usp.br/atividades/index.html, acessada em Julho 2011. 23. http://www.cdcc.usp.br/quimica/index.html, acessada em Julho 2011.

24. http://quimica2011.org.br/, acessada em Julho 2011; http://www. chemistry2011.org/, acessada em Julho 2011.

25. Luz, D. M.; Oliveira, W. C.; Augusto, R. A.; Massone, C. A.; Casa da Descoberta: o público e as ações de divulgação científica, XVII Simpósio Nacional de Ensino de Física, 2007, http://www.sbf1.sbfisica. org.br/eventos/snef/xvii/sys/resumos/T0470-2.pdf, acessada em Julho 2011.

26. Albertin, R.; Arribas, M. A. G.; Bastos, E. L.; Röpke, S.; Sakai, P. N.; Sanches, A. M. M.; Stevani, C. V.; Umezu, I. S.; Yu, J.; Baader, W. J.; Quim. Nova 1998, 21, 772.

27. Souza, N. A.; Ribeiro, C. M. R.; Borges, M. N.; Trales, P. R.; Rev. Iberoam. Educ. 2008, 46, 1.

28. Ribeiro, A. C. G.; Monografia de Final de Curso de Química, Universidade Federal Fluminense, Brasil, 2010.

29. Borges, M. N.; Luz, D. M.; Oliveira, W. C.; Formação continuada de monitores na Casa da Descoberta, $4^{\circ}$ CBEU, 2009, www.cbeu.ufgd.edu. br/arquivos/apresentacoes_posteres.pdf, acessada em Julho 2011.

30. Andrade, B.; Museus sustentáveis: estudo de caso da Casa da Descoberta na Universidade Federal Fluminense, http://www. arqmuseus.fau.ufrj.br/anais-seminario_2010/eixo_iii/p3-6_barbara_ andrade.pdf, acessada em Julho 2011.

31. Ribeiro, C. M. R.; Luz, D. M.; Borges, M. N., orgs.; Cadernos de Experimentos e Curiosidades da Química na Casa da Descoberta, $2^{\mathrm{a}}$ ed., Eduff: Niterói, 2011.

32. http://oglobo.globo.com/educacao/mat/2010/01/19/casa-da-descobertada-uff-uma-programacao-para-as-ferias-915567081.asp, acessada em Julho 2011. 